issue concerns the role of proton pump inhibitors (PPIs) in promoting CDAD. Other factors that elevate the risk of CDAD include older age, recent gastrointestinal surgery and immunocompromising therapy. The use of PPIs may augment these risks in such patients.

Many infection control measures have been implemented, including contact precautions, dedicated equipment for infected patients when possible, disposable thermometers, early empirical treatment of suspected cases, infection prevention and control education for personnel, an emphasis on hand hygiene, intensified housekeeping in high-incidence units, sporicidal agents for environmental disinfection, review and potential restriction of antibiotics, and decreased turnaround time for $C$. difficile test results.

Despite these measures, no hospital in our group has been able to bring the CDAD rate to its pre-epidemic rate. Why have we not been able to break the cycle of transmission? Several obstacles hamper control measures. In an outbreak situation, spore burdens are high and require increasing intensity of environmental disinfection. In most hospitals, the housekeeping staff was already working at full capacity before the outbreak. Overburdened health care workers have had difficulty coping with the increased numbers of patients in isolation. Inadequate numbers of single rooms with dedicated bathroom facilities also facilitate transmission. Let us remember that other infectious patients also require vigilant isolation, such as those with MRSA, VRE, measles, chicken pox and tuberculosis, to name a few. The paucity of adequate handwashing facilities further compounds the problem. Improved methods to monitor antibiotic utilization are required. Taken together, this highlights the lack of surge capacity to fully combat the outbreak.

A number of unanswered questions remain. If this current strain is different, where has it come from? Why do some infected patients have serious complications, while other seemingly similar patients experience a relatively benign course? How can we prevent the occurrence of severe complications?
The answers to these questions would improve our understanding of this disease and its control. It is only through a concerted and coordinated approach, coupled with increased resources and funding, that expeditious answers will be found to the current dilemma and patient safety will be assured.

The authors are members of the Clostridium difficile Associated Diarrhea Clinical Study Investigators Group. Their affiliations appear in an online appendix (available at www.cmaj.ca/cgi/content/full/171/1/47/DC1)

Competing interests: None declared.

Contributors: Vivian Loo initiated and coordinated the commentary and, with Michael Libman and Mark Miller, drafted the commentary. All authors provided data included in the commentary, revised the draft critically for important intellectual content and approved the final version.

\section{References}

1. Poutanen SM, Simor AE. Clostridium difficile-associated diarrhea in adults [review]. CMA7 2004;171(1):51-8.

2. Archibald LK, Banerjee SN, Jarvis WR. Secular trends in hospital-acquired Clostridium difficile disease in the United States, 1987-2001. F Infect Dis 2004; 189:1585-9.

3. Hyland M, Ofner-Agostini M, Miller M, Paton S, Gourdeau M, Ishak M Nosocomial Clostridium difficile-associated diarrhea in Canada: results of the Canadian Nosocomial Infection Surveillance Program (CNISP). 1997 NCDAD prevalence Surveillance Project. Can 7 Infect Dis 2001;12(2):81-8.

4. Miller MA, Hyland M, Ofner-Agostini M, Gourdeau M, Ishak M. Morbidity, mortality, and healthcare burden of nosocomial Clostridium difficile-associated diarrhea in Canadian hospitals. Infect Control Hosp Epidemiol 2002;23:137-40.

5. Olson MM, Shanholtzer CJ, Lee JT, Gerding DN. Ten years of prospective Clostridium difficile-associated disease surveillance and treatment at the Minneapolis VA Medical Center. Infect Control Hosp Epidemiol 1994;15:371-81.

6. Prendergast TM, Marini CP, D'Angelo AJ, Sher ME, Cohen JR. Surgical patients with pseudomembranous colitis: factors affecting prognosis. Surgery 1994;116:768-74.

7. Pittet D, Mourouga P, Perneger TV. Compliance with handwashing in a teaching hospital. Infection Control Program. Ann Intern Med 1999;130(2):126-30.

8. Dial S, Alrasadi K, Manoukian C, Huang A, Menzies D. Risk of Clostridium difficile diarrhea among hospital inpatients prescribed proton pump inhibitors: cohort and case-control studies. CMA7 2004;171(1):33-8.

Correspondence to: Dr. Vivian G. Loo, Infection Control Service, Hôpital général de Montréal, D16.168-1650 ave. Cedar, Montréal QC H3G 1A4; fax 514 934-8427; vivian.loo@muhc.mcgill.ca

\title{
Glycemic self-monitoring and insurance coverage
}

\section{Michele Heisler}

ß S See related article page 39

A growing body of research is calling attention to significant rates of medication underuse and to adverse health consequences associated with high out-ofpocket drug costs, especially among patients with low incomes, multiple chronic illnesses or no prescription drug coverage. ${ }^{1,2}$ Studies in the United States and Canada have shown that public- and private-sector policies limiting drug coverage lead to fewer prescriptions being filled, ${ }^{3,4}$ higher rates of nursing home admissions ${ }^{5}$ and increased use of acute care services. ${ }^{3}$ Yet physicians often fail to identify patients who are burdened by high out-of-pocket expenses. ${ }^{6}$ Many patients with chronic illnesses who report having underused medications because of cost never discuss this underuse with their physicians. ${ }^{7,8}$

In this issue Samantha Bowker and colleagues ${ }^{9}$ (see page 39) contribute to this body of research and expand the policy debate on the scope of health insurance coverage into the realm of medical supplies. They examine cross-sectional baseline survey and laboratory data from 405 non-insulin-using patients with type 2 diabetes who are enrolled in a randomized controlled trial designed to assess the effect of providing free blood glucose testing supplies on glycemic control. Of these patients, $41 \%$ had at least some level of insurance coverage for blood 
glucose testing supplies. In multivariate analyses adjusted for age, income, education, frequency of monitoring and perceived barriers to monitoring, they found that patients with insurance coverage of testing supplies had hemoglobin $\mathrm{A}_{\mathrm{lc}}$ values that were $0.5 \%$ higher than the values for patients without such insurance coverage $(p=0.006)$. As the authors note, this finding is clinically significant. There were even larger differences among people with poorer baseline glycemic control (hemoglobin $A_{1 c}$ concentrations $>8.4 \%$ ). These findings reinforce those of Soumerai and coauthors ${ }^{10}$ who examined trends in hemoglobin $\mathrm{A}_{\mathrm{lc}}$ concentrations 2 years before and after a large US health maintenance organization instituted coverage of blood glucose testing supplies. In that study, among the 288 patients who initiated self-monitoring of blood glucose, mean hemoglobin $\mathrm{A}_{\mathrm{lc}}$ concentrations fell from $10.8 \%$ to $8.6 \%$.

If the current study's findings are confirmed by subsequent results from the authors' randomized controlled trial, they will have important implications for the ongoing policy debate in Canada. Approximately 6\% of Canadians have diabetes, and the prevalence of the disease is projected to increase by $35 \%$ over the next 25 years. ${ }^{11}$ The total economic burden of diabetes in Canada is estimated to exceed US\$5 billion a year. ${ }^{11}$ Policy decisions determining which medications, procedures or supplies to cover should be based on sound scientific evidence of clinical benefit. Certainly, blood glucose testing supplies are expensive. However, for conditions such as diabetes whose associated morbidity and mortality are high, the greater the clinical benefit, the less significant are the costs of coverage relative to the downstream costs of treating complications of the disease.

Although Bowker and colleagues' findings are provocative, they must be considered in the context of the mixed findings of earlier research on self-monitoring among patients with type 2 diabetes who do not take insulin. ${ }^{12}$ In the face of limited empirical evidence, proponents argue that self-monitoring is an effective tool to guide patients and physicians in modifying diabetes management (including diet, physical activity and medication). Indeed, studies that have shown improved glycemic control with self-monitoring — even among patients taking insulin have tended to be those in which self-monitoring was directly linked to concrete steps (such as titrating insulin doses) that patients could take in response to those values. ${ }^{12,13} \mathrm{Few}$ trials have examined the influence of self-monitoring on other modifiable behaviours such as diet and exercise. ${ }^{12}$ Yet self-monitoring appears most likely to play a significant role in improving glycemic control when it is an integral part of broader efforts to support diabetes self-management.

What, then, might be the mechanism for this study's observed effect of insurance coverage for self-monitoring supplies on glycemic control? Certainly, as the authors hypothesize, it could simply be the removal of a financial obstacle. One might then anticipate that those without coverage, who indeed were more likely to report cost as a barrier to self-monitoring, might also report a lower frequency of testing. However, frequency of self-monitoring did not appear to be independently associated with glycemic control. It is also possible that having insurance coverage - especially if patients had to choose to purchase private coverage on their own or proactively apply for supplemental coverage - is a marker for increased concern about health and involvement in diabetes self-care.

This study alerts us to an association between insurance coverage for blood glucose testing supplies and glycemic control. As Bowker and colleagues note, their randomized controlled trial of free self-monitoring supplies versus "usual health care policy" will more definitively establish the effect of covering these supplies and reduce concerns that other unmeasured attributes might account for the observed differences between the study groups.

This study reinforces several crucial messages for physicians. As with other possible obstacles to effective diabetes self-management, we must discuss with our patients the financial barriers they may be facing. More broadly, we must explore with patients the entire range of factors that they weigh when choosing whether and how to take prescribed medications or to engage in other diabetes self-care activities. Translating effective diabetes treatment regimens into improved clinical outcomes depends on patients' capacity and motivation to initiate and sustain those regimens.

Dr. Heisler is from the Ann Arbor VA Center for Practice Management and Outcomes Research and the Division of General Medicine, University of Michigan Health System, Ann Arbor, Mich.

Competing interests: None declared.

\section{References}

1. Steinman MA, Sands LP, Covinsky KE. Self-restriction of medications due to cost in seniors without prescription coverage. 7 Gen Intern Med 2001;16:793-9.

2. Piette JD, Wagner TH, Potter MB, Schillinger D. Health insurance status, medication self-restriction due to cost, and outcomes among diabetes patients in three systems of care. Med Care 2004;42:102-9.

3. Tamblyn R, Laprise R, Hanley JA, Abrahamowicz M, Scott S, Mayo N, et al. Adverse events associated with prescription drug cost-sharing among poor and elderly persons. $7 A M A$ 2001;285:421-9.

4. Soumerai SB, Avorn J, Ross-Degnan D, Gortmaker S. Payment restrictions for prescription drugs under Medicaid. Effects on therapy, cost, and equity. $N$ Engl 7 Med 1987;317:550-6.

5. Soumerai SB, Ross-Degnan D, Avorn J, McLaughlin T, Choodnovskiy I. Effects of Medicaid drug-payment limits on admission to hospitals and nursing homes. N Engl 7 Med 1991;325:1072-7.

6. Heisler M, Wagner TH, Piette JD. Clinician identification of chronically ill patients who have problems paying for prescription medications. Am 7 Med 2004;116:753-8.

7. Alexander GC, Casalino LP, Meltzer DO. Patient-physician communication about out-of-pocket costs. FAMA 2003;290:953-8.

8. Piette JD, Heisler M, Wagner TH. Cost-Related Medication Underuse: do patients with chronic illnesses tell their doctors? Arch Intern Med [In press].

9. Bowker SL, Mitchell CG, Majumdar SR, Toth EL, Johnson JA. Lack of insurance coverage for testing supplies is associated with poorer glycemic control in patients with type 2 diabetes. CMA7 2004;171(1):39-43.

10. Soumerai S, Mah C, Zhang F, Adams A, Barton M, Ross-Degnan D. Effects of HMO coverage of diabetes self-monitoring devices on rates of self-monitoring, medication compliance, and blood glucose control. In: AcademyHealth 2002 Annual Research Meeting Abstracts. Available: www.academyhealth.org/2002/abstracts/pharmaceutical.pdf (accessed 2004 June 01).

11. Dawson KG, Gomes D, Gerstein H, Blanchard JF, Kahler KH. The economic cost of diabetes in Canada, 1998. Diabetes Care 2002;25:1303-7.

12. The Canadian Coordinating Office for Health Technology Assessment (CCOHTA). Pre-Assessment Diabetes Testing. May 2004, Number 34. Available: http://www.ccohta.ca/entry_e.html (accessed 2004 June 01).

13. Franciosi M, Pellegrini F, De Berardis G, Belfiglio M, Cavaliere D, Di Nardo $\mathrm{B}$, et al. The impact of blood glucose self-monitoring on metabolic control and quality of life in type 2 diabetic patients: an urgent need for better educational strategies. Diabetes Care 2001;24:1870-7.

Correspondence to: Dr. Michele Heisler, Division of General

Medicine, University of Michigan Health System, PO Box 130170, Ann Arbor MI 48113; 734 761-2939; mheisler@med.umich.edu 